Wright State University

CORE Scholar

$12-2019$

\title{
Totally Robotic vs Hybrid Abdominoperineal Resection: A Retrospective Multicenter Analysis
}

Jonathan Douissard

Vincent Obias

Craig S. Johnson

Monika E. Hagen

Deborah Keller

See next page for additional authors

Follow this and additional works at: https://corescholar.libraries.wright.edu/surg

Part of the Surgery Commons

\section{Repository Citation}

Douissard, J., Obias, V., Johnson, C. S., Hagen, M. E., Keller, D., Ouellette, J. R., \& Hellan, M. (2019). Totally Robotic vs Hybrid Abdominoperineal Resection: A Retrospective Multicenter Analysis. The International Journal of Medical Robotics and Computer Assisted Journal, 1-7.

https://corescholar.libraries.wright.edu/surg/775

This Article is brought to you for free and open access by the Surgery at CORE Scholar. It has been accepted for inclusion in Department of Surgery Faculty Publications by an authorized administrator of CORE Scholar. For more information, please contact library-corescholar@wright.edu. 


\section{Authors}

Jonathan Douissard, Vincent Obias, Craig S. Johnson, Monika E. Hagen, Deborah Keller, James R. Ouellette, and Minia Hellan 


\title{
Totally robotic vs hybrid abdominoperineal resection: A retrospective multicenter analysis
}

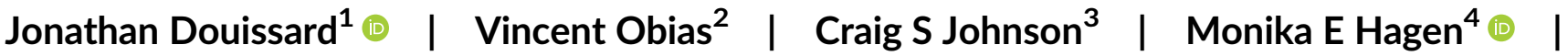 \\ Deborah Keller $^{5}$ | James R Ouellette ${ }^{6}$ | Minia Hellan ${ }^{7}$
}

${ }^{1}$ Visceral Surgery Department, Geneva University Hospital, Geneva, Switzerland

${ }^{2}$ Division of Colorectal Surgery, Department of Surgery, George Washington University Hospital, Washington, DC

${ }^{3}$ Oklahoma Surgical Hospital, Tulsa, Oklahoma

${ }^{4}$ Visceral Surgery Department,

Geneva University Hospital, Geneva,

Switzerland

${ }^{5}$ Division of Colorectal Surgery, Department of Surgery, New York Presbyterian HospitalColumbia University Medical Center,

New York, New York

${ }^{6}$ Surgical Oncology Division, Wright State University - Boonshoft School of Medicine, Centerville, Ohio

${ }^{7}$ Wright State University - Boonshoft School of Medicine, Kettering Cancer Care, Kettering, Ohio

\section{Correspondence}

Dr Minia Hellan, Wright State UniversityBoonshoft School of Medicine, Kettering Cancer Care, 3700 Southern Blvd Ste 401, Kettering, OH 45429-1226.

Email: minia.hellan@wright.edu

\begin{abstract}
Introduction: Laparoscopic abdominoperineal resection (APR) for low rectal cancers is technically demanding. Robotic assistance may be of help and can be hybrid (HAPR) or totally robotic (RAPR). The present study describes outcomes of robotic APR and compares both approaches.

Material and methods: A multicentric retrospective analysis of rectal cancer patients undergoing either HAPR or RAPR was conducted. Patients' demographics, surgeons' experience, oncologic results, and intraoperative and postoperative outcomes were collected.

Results: One hundred twenty-five patients were included, 48 in HAPR group and 77 in RAPR group. Demographics and comorbidities were comparable. Operative time was reduced in RAPR group $(266.9 \pm 107.8 \mathrm{~min}$ vs $318.9 \pm 75.1 \mathrm{~min}, P=.001)$. RAPR patients were discharged home more frequently $(91.18 \%$ vs $66.67 \%, P=.001)$, and experienced fewer parastomal hernias (3.71\% vs $9.86 \%, P=.001$ ).

Conclusion: RAPR is safe and feasible with appropriate oncologic outcomes. Totally robotic approach reduces operative time and may improve functional outcomes.

\section{KEYWORDS}

abdominoperineal excision, abdominoperineal resection, rectal cancer, rectal surgery, robotic surgery
\end{abstract}

\section{$1 \mid$ INTRODUCTION}

Rectal cancer surgery encompasses different types of surgical resections. Their indications and techniques are subject to constant debate and evolution. ${ }^{1}$ When reconstruction is not feasible for oncologic, technical, or patient-related reasons, abdominoperineal resection (APR) with permanent colostomy remains the only alternative. This procedure is however associated with higher morbidity and cancer recurrence rate. ${ }^{2}$ Although traditionally performed through an open approach, growing evidence suggests that minimally invasive APR could reduce morbidity with acceptable oncologic results. ${ }^{3}$ Laparoscopic APR is technically very demanding; the long rigid instruments are often insufficient in the narrow pelvic space. A robotic approach could overcome these limitations and has gained popularity in rectal cancer surgery over the past decade. ${ }^{4}$ Its current role is not yet defined because of lack of evidence, but available data suggest that it may be of significant help for difficult pelvic dissections, especially in anatomically challenging and obese patients. ${ }^{5-7} \mathrm{Ng}$ et al published the first description of hybrid robotic APR in $2007,{ }^{8}$ with laparoscopic colonic mobilization and robotic rectal dissection. Descriptions of fully robotic ${ }^{9}$ and single-port robotic procedures ${ }^{10}$ were published thereafter. A recent retrospective analysis of the National Inpatient Sample database (Healthcare Cost and Utilization Project, United States) showed that robotic APR may reduce conversion rate and hemorrhagic complications, but significantly increases inhospital costs compared with open and laparoscopic APR. ${ }^{11}$ These data, however, are pulled from a nationwide database and thus provide few details about surgical technique, intraoperative outcomes, and pathological results. Analyzing retrospectively 21 robotic APR compared with 
open APR, Kim et $\mathrm{al}^{12}$ showed improved oncologic outcomes in the robotic group. Eftaiha et $\mathrm{al}^{13}$ found similar results comparing retrospectively 22 robotic APR with laparoscopic cases. Small number of patients limit these studies, but large sample size is difficult to obtain for such a highly specialized procedure.

When choosing robotic assistance for APR, the surgeon can decide between a hybrid laparoscopic-robotic (HAPR) or totally robotic approach (RAPR). HAPR are often preferred in early robotic experience. The RAPR however, by improving workflow and ergonomics, may lead to more efficient and potentially cheaper procedures. Decreasing operative time and abdominal wall manipulations could reduce surgical trauma, thus improving postoperative outcomes and reducing recovery time. These outcomes improvements as well as the reduced number of instruments needed as compared with hybrid approach may optimize cost-efficiency, which is always of interest in robotic surgery. Data comparing hybrid and totally robotic procedures in general, and especially in the field of rectal surgery, are scarce.

The purpose of this study is to explore outcomes of robotic abdominoperineal resection in a large cohort of patients and determine whether RAPR or HAPR approach should be favored in further development of this technique.

\section{2 | MATERIAL AND METHODS}

\subsection{Study design and participants}

We conducted a retrospective analysis of patients who underwent robotic APR in six US centers between November 2008 and March 2016 for low to ultra-low rectal cancers (less than $7 \mathrm{~cm}$ from anal verge) or anal canal cancers requiring APR due to tumor specifics or patient related issues (sphincter involvement, pre-existing incontinence or poor sphincter function, comorbidities, and age). Seven surgeons trained in colorectal surgery or surgical oncology of various robotic experience were involved. All consecutive cancer patients who underwent robotic APR during this period were included.

\section{2 | Technique}

Abdominoperineal resection using either totally robotic or hybrid approach were performed as per the surgeon's personal preference. Both robotic systems (Si or Xi DaVinci surgical system (Intuitive Surgical Inc Sunnyvale, CA) were used depending on availability at the different institutions. In HAPR, the left colon mobilization and ligation of inferior mesenteric artery were performed laparoscopically, and the robotic system was docked only for the rectal dissection. In the RAPR approach, the abdominal part of the procedure was also performed robotically. Figure 1 shows standard trocars placement for RAPR using the Xi system. Surgical approach (hybrid or totally robotic), and surgical technique and position for perineal part of procedure (prone vs lithotomy) were chosen depending on surgeon's preference and experience. A total mesorectal excision was attempted in all cases. The levator muscles were divided

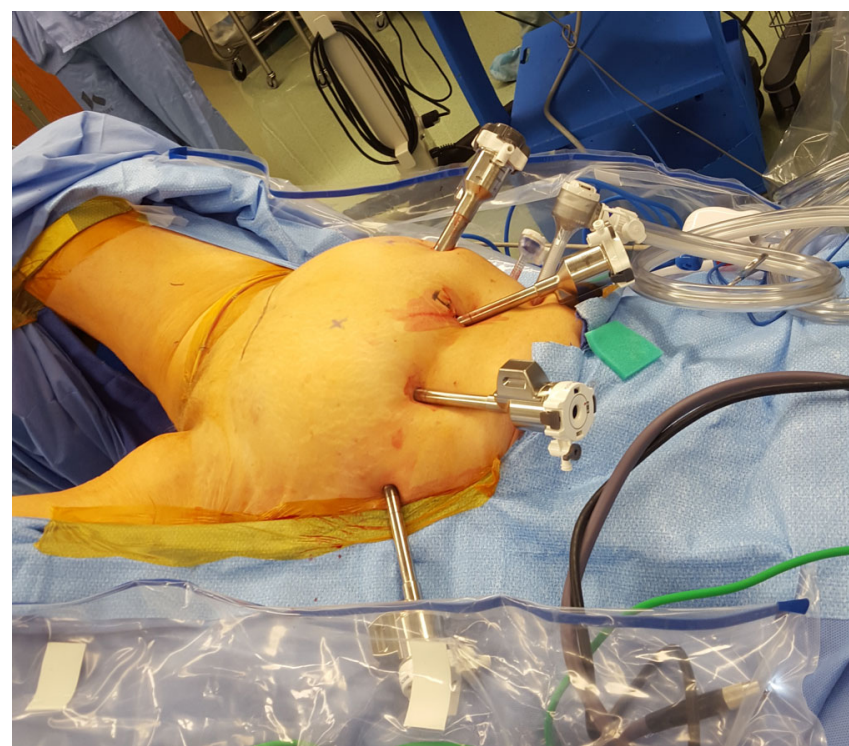

FIGURE 1 standard trocars positioning for totally robotic APR using Xi system

either transabdominally using the robot, or from below during the perineal part of the procedure. Standard or cylindrical APR resection was chosen depending on preoperative imaging and tumor involvement of the pelvic floor. Closure of the perineal defect included primary closure, placement of mesh or muscle-flaps. The stomas were performed in a standard fashion, without any prophylactic mesh reinforcement.

\section{3 | Data collection}

Patients' demographics and comorbidities, tumor stage, tumor type, and any neoadjuvant treatment received were recorded. Surgical technique data included surgical approach (HAPR vs RAPR), as well as position and technique of perineal dissection. Surgeons' experience was classified according to their volume of robotic APR. Surgeons who had performed less than 10 robotic APRs were considered low volume, surgeons with more the 10 cases high volume surgeons.

Surgical outcomes were recorded intraoperatively (operative time, conversion, complication, transfusion) and postoperatively (complications at 30 days, survival and local recurrence, length of follow-up, readmission rate at 30 days and reoperation rate at 30 and 60 days). Pathological outcomes included tumor size and location, tumor staging according to the eighth edition of American Joint Committee on Cancer (AJCC) staging manual, ${ }^{14}$ completeness of mesorectum, positivity of circumferential resection margins (CRM), specimen perforation, and lymph nodes status.

\subsection{Ethical statement}

All procedures were in accordance with ethical standards of institutional and national research committee and with the 1964 Helsinki 
Declaration and its later amendments or comparable ethical standards. This is a retrospective analysis and all data used in this manuscript were obtained from an institutional-quality database. There are no patient identifiers included in the publicly available data, and thus, patient consent and institutional review board are not required.

\subsection{Statistics}

Statistical analysis was carried with Stata 15.0 software (Stata Corp, College Station, TX). $P$ value lower than .05 was considered statistically significant. Continuous data were analyzed using Student $t$ test or the Mann-Whitney test when data were not normally distributed. Binary and categorical data were analyzed using chi-squared test or the Fisher exact test when expected effects were lower than 5. Considering the retrospective nature of these data and potential confounding factors, outcomes of interest identified in univariable analysis were tested using multivariable linear and logistic regression analysis.

Multivariable model for intraoperative outcomes and pathological results included type of approach (RAPR or HAPR), obesity (defined by body mass index [BMI] of more than $30 \mathrm{~kg} / \mathrm{m}^{2}$ ), previous abdominal surgery, surgeon's experience, intraoperative complication, and eventual additional procedure.

Multivariable model for postoperative outcomes included type of approach (RAPR or HAPR), age (older than or younger than 75 years old), obesity (defined by BMI of more than $30 \mathrm{~kg} / \mathrm{m}^{2}$ ), previous abdominal surgery, surgeon's experience, intraoperative complication, eventual additional procedure, overall comorbidities, and length of follow-up (more than or less than 24 months).

\section{$3 \mid$ RESULTS}

In total, 125 patients were included, 48 in HAPR group and 77 in RAPR group. Seven surgeons in six US hospitals participated in this study, three of them considered high volume surgeons in terms of robotic APR experience who accounted for $95.8 \%$ of HAPR and $77.9 \%$ of RAPR. Patients' demographics and comorbidities were not statistically different among groups, except significantly more previous abdominal surgery in RAPR patients (66.2\% vs $41.7 \%, P=.007)$, and higher rates of hypertension ( $58.4 \%$ vs $35.4 \%, P=.012$ ). Other patients' and tumors' characteristics at baseline are described in Table 1.

Regarding surgical technique, prone position for the perineal resection was only used in $10.4 \%$ of patients of the RAPR group $(P=.021)$. Cylindrical perineal resection was significantly more frequent in RAPR group ( $45.5 \%$ vs $4.17 \%, P<.001$ ), as well as transabdominal division of levator muscles $(61.0 \%$ vs $6.2 \%, P<.001)$. Additional procedures were not statistically different among groups $(P=.373)$. Lysis of adhesions, vaginal wall resection and reconstruction, gracilis or rectus flap were the most frequently performed additional procedures. Other surgical technique details were not statistically different and can be found in Table 2 .
TABLE 1 Patients' characteristics at time of surgery

\begin{tabular}{|c|c|c|c|}
\hline Parameter & $\begin{array}{l}\text { Hybrid APR } \\
(\mathrm{n}=48)\end{array}$ & $\begin{array}{l}\text { Robotic } \\
\text { APR } \\
(n=77)\end{array}$ & $P$ value \\
\hline Age (years), mean (SD) & $62.5(12.0)$ & $61.2(11.0)$ & .269 \\
\hline Gender & & & .081 \\
\hline Male, n (\%) & $36(75)$ & $46(59.7)$ & \\
\hline Female, n (\%) & $12(25)$ & $31(40.3)$ & \\
\hline $\begin{array}{l}\text { Body mass index }\left(\mathrm{kg} / \mathrm{m}^{2}\right) \text {, mean } \\
\text { (SD) }\end{array}$ & $28.3(6.0)$ & $27.2(6.9)$ & .173 \\
\hline $\begin{array}{l}\text { Previous intra-abdominal surgery, } \\
\mathrm{n}(\%)\end{array}$ & & & .007 \\
\hline No & $28(58.3)$ & $26(33.8)$ & \\
\hline Yes & $20(41.7)$ & $51(66.2)$ & \\
\hline \multicolumn{4}{|l|}{ Co-morbidities, n (\%) } \\
\hline Obesity & $18(37.5)$ & $18(23.4)$ & .090 \\
\hline Coronary Artery Disease & $8(16.7)$ & $5(6.5)$ & .070 \\
\hline Hypertension & $17(35.4)$ & $45(58.4)$ & .012 \\
\hline Diabetes & $10(20.8)$ & $9(111.7)$ & .166 \\
\hline Overall & $29(60.4)$ & $59(76.6)$ & .054 \\
\hline Surgeons' experience, n (\%) & & & .007 \\
\hline Low volume & $2(4.2)$ & $17(22.1)$ & \\
\hline High volume & $46(95.8)$ & 60 (77.9) & \\
\hline \multicolumn{4}{|l|}{ Tumor type, n(\%) } \\
\hline Rectal adenocarcinoma & $40(85.1)$ & $64(83.1)$ & .770 \\
\hline $\begin{array}{l}\text { Recurrent rectal } \\
\text { adenocarcinoma }\end{array}$ & $4(8.5)$ & $2(2.6)$ & .137 \\
\hline Rectal squamous cell cancer & $1(2.1)$ & $9(11.7)$ & .088 \\
\hline Anal adenocarcinoma & $1(2.1)$ & $0(0)$ & .379 \\
\hline $\begin{array}{l}\text { Ulcerative colitis with multifocal } \\
\text { signet cell cancer }\end{array}$ & $0(0)$ & $1(0)$ & 1.0 \\
\hline Melanoma & $0(0)$ & $1(0)$ & 1.0 \\
\hline $\begin{array}{l}\text { Gastro-intestinal stromal tumor } \\
\text { (GIST) }\end{array}$ & $1(2.1)$ & $0(0)$ & .379 \\
\hline Neodjuvant treatment, $\mathrm{n}(\%)$ & & & .807 \\
\hline Yes & $43(89.6)$ & $70(90.9)$ & \\
\hline No & $5(10.4)$ & $7(9.1)$ & \\
\hline
\end{tabular}

Significant reduction of operative time was observed in the RAPR group ( $266.9 \pm 107.8 \mathrm{~min}$ vs $318.9 \pm 75.1 \mathrm{~min}, P=.001$ ) (Table 3 ). Rate of conversion was $2.6 \%$ in the RAPR group and $6.4 \%$ in the HAPR group $(P=.371)$. Intraoperative complication rate was similar between groups ( $15.6 \%$ in RAPR vs $16.7 \%$ in HAPR, respectively), however specimen perforation was almost twice more frequent in the HAPR group (12.5\%) as compared with the RAPR group (6.5\%) $(P=.332)$.

Mean tumor size was $1 \mathrm{~cm}$ higher in RAPR group $(P=.093)$ and tumors were almost $1 \mathrm{~cm}$ closer from anal verge in this group $(P=.006)$ (Table 3). Pathological staging was comparable between groups. CRM involvement was found in $18.75 \%$ of HAPR patients and $14.29 \%$ of RAPR patients $(P=.508)$. 
TABLE 2 Surgical technique and intra-operative outcomes

\begin{tabular}{|c|c|c|c|}
\hline Parameter & $\begin{array}{l}\text { Hybrid } \\
\text { APR } \\
(n=48)\end{array}$ & $\begin{array}{l}\text { Robotic } \\
\text { APR } \\
(n=77)\end{array}$ & $P$ value \\
\hline Perineal resection position, $\mathrm{n}(\%)$ & & & .021 \\
\hline Lithotomy & $48(100)$ & $69(89.6)$ & \\
\hline Prone & $0(0)$ & $8(10.4)$ & \\
\hline Perineal resection, $\mathrm{n}(\%)$ & & & $<.001$ \\
\hline Cylindrical & $2(4.2)$ & $35(45.5)$ & \\
\hline Standard & $46(95.8)$ & $42(54.6)$ & \\
\hline Closure of perineal defect, $\mathrm{n}(\%)$ & & & .516 \\
\hline Primary & $46(95.8)$ & $69(89.6)$ & \\
\hline Flap & $2(4.2)$ & $5(6.5)$ & \\
\hline Mesh & $0(0)$ & $1(1.3)$ & \\
\hline Flap and mesh & $0(0)$ & $2(2.6)$ & \\
\hline Division of levator muscle, $n$ (\%) & & & $<.001$ \\
\hline Below & 45 (93.8) & $30(39.0)$ & \\
\hline Transabdominal & $3(6.2)$ & $47(61.0)$ & \\
\hline Additional procedure, $\mathrm{n}(\%)$ & $20(41.7)$ & $26(33.8)$ & .373 \\
\hline \multicolumn{4}{|l|}{ Operating time (min), mean (SD) } \\
\hline \multicolumn{4}{|l|}{ Conversion, n (\%) } \\
\hline Overall & $3(6.3)$ & $2(2.6)$ & .371 \\
\hline To open surgery & $2(4.2)$ & $2(2.6)$ & .638 \\
\hline To hand assisted laparoscopy & $1(2.1)$ & $0(0)$ & .384 \\
\hline \multicolumn{4}{|l|}{$\begin{array}{l}\text { Intraoperative } \\
\text { complications, n (\%) }\end{array}$} \\
\hline Overall & $8(16.7)$ & $12(15.6)$ & .872 \\
\hline Bleeding & $3(6.3)$ & $6(7.8)$ & 1.000 \\
\hline Require transfusion & $4(8.3)$ & $9(11.7)$ & .550 \\
\hline Specimen perforation & $6(12.5)$ & $5(6.5)$ & .332 \\
\hline Urethral injury & $0(0)$ & $3(3.9)$ & .285 \\
\hline
\end{tabular}

Similarly, completeness of mesorectal resection was not statistically different between groups. Mean number of lymph nodes retrieved in both groups were above recommendations from AJCC (12 lymph nodes), although significantly more lymph nodes were retrieved in the HAPR group $(20.71 \pm 16.13$ vs 15.14 $\pm 11.27, P=.020$ ).

Home discharge was significantly more frequent after RAPR than after HAPR $(91.18 \%$ vs $66.67 \%, P=.001)$. In-hospital length of stay, perineal wound complications, pelvic abscess rate, readmission, and reoperation within 30 days were slightly improved in the RAPR group, although not statistically significant (Table 4). Readmissions within 30 days were for wound infections or pelvic abscess (four in each group), dehydration or deconditioning (one of each in each group) and small bowel obstruction (SBO) (four in the HAPR group and two in the RAPR group). In the HAPR group, three patients needed reoperation for SBO and one for wound debridement. In the RAPR group, one patient needed percutaneous
TABLE 3 Pathology findings

\begin{tabular}{|c|c|c|c|}
\hline Parameter & $\begin{array}{l}\text { Hybrid } \\
\text { APR } \\
(n=48)\end{array}$ & $\begin{array}{l}\text { Robotic } \\
\text { APR } \\
(n=77)\end{array}$ & $P$ value \\
\hline Tumor size (cm), mean (SD) & $2.75(2.0)$ & $3.26(1.9)$ & .093 \\
\hline $\begin{array}{l}\text { Distance from anal verge }(\mathrm{cm}) \text {, } \\
\text { mean (SD) }\end{array}$ & $4.13(0.3)$ & $3.28(0.2)$ & .006 \\
\hline Pathological staging, (\%) & & & .288 \\
\hline 0 & $5(10.4)$ & $13(16.9)$ & \\
\hline 1 & $14(29.2)$ & $17(22.1)$ & \\
\hline $2 a$ & $11(22.9)$ & $19(24.7)$ & \\
\hline $2 b$ & $0(0)$ & $0(0)$ & \\
\hline $2 c$ & $0(0)$ & $6(7.8)$ & \\
\hline $3 a$ & $4(8.3)$ & $3(3.9)$ & \\
\hline $3 b$ & $7(14.6)$ & $11(14.3)$ & \\
\hline $3 c$ & $3(6.3)$ & $1(1.3)$ & \\
\hline 4 & $4(8.3)$ & $7(9.1)$ & \\
\hline Resection, (\%) & & & .576 \\
\hline 0 & 39 (81.3) & $67(87.0)$ & \\
\hline 1 & 8 (16.7) & 9 (11.7) & \\
\hline 2 & $1(2.1)$ & $1(1.3)$ & \\
\hline $\begin{array}{l}\text { Circumferential margin } \\
\text { involvement, (\%) }\end{array}$ & & & .508 \\
\hline Negative & $39(81.3)$ & $66(85.7)$ & \\
\hline Positive & 9 (18.8) & $11(14.3)$ & \\
\hline $\begin{array}{l}\text { Mesorectal resection quality, } \\
\text { (\%) }\end{array}$ & & & .650 \\
\hline Complete & $21(43.8)$ & $35(45.5)$ & \\
\hline Near complete & 9 (18.8) & 9 (11.7) & \\
\hline Incomplete & $6(12.5)$ & $14(18.2)$ & \\
\hline Missing data & $12(25.0)$ & $19(24.7)$ & \\
\hline Specimen perforation, (\%) & & & .332 \\
\hline Yes & $6(12.5)$ & $5(6.5)$ & \\
\hline No & $42(87.5)$ & $72(93.5)$ & \\
\hline $\begin{array}{l}\text { Lymph nodes retrieved } \\
\text { (number), mean (SD) }\end{array}$ & $20.71(16.1)$ & $15.14(11.3)$ & .020 \\
\hline
\end{tabular}

endoscopic gastrostomy (PEG) for re-alimentation, two needed reoperation for SBO, one for flap debridement and one for excision of positive margins.

At long-term follow-up, parastomal hernia rate was lower after RAPR (9.86\% vs $3.71 \%, P=.001$ ); although length of follow-up was significantly lower in this group $(14.38 \pm 13.77$ months vs 25.58 \pm 17.15 months, $P<.001$ ).

After multivariate linear regression, reduction of operative time in the RAPR group remained statistically significant (coefficient $-69.87 \mathrm{~min}, P<.001$ ), independently from two confirmed confounding factors: surgeons' experience (coefficient $-135.32 \mathrm{~min}$, $P<.001$ ) and additional concomitant procedure (coefficient $+46.32 \mathrm{~min}, P=.003$ ). Other variables integrated in the multivariate 
TABLE 4 Post-operative outcomes

\begin{tabular}{|c|c|c|c|}
\hline Parameter & $\begin{array}{l}\text { Hybrid } \\
\text { APR } \\
(n=48)\end{array}$ & $\begin{array}{l}\text { Robotic } \\
\text { APR } \\
(n=77)\end{array}$ & $P$ value \\
\hline $\begin{array}{l}\text { Patients with stay on ICU, } \mathrm{n} \\
\text { (\%) }\end{array}$ & $6(12.50)$ & 11 (14.29) & .777 \\
\hline \multicolumn{4}{|l|}{$\begin{array}{l}\text { Post-operative wound } \\
\text { complications } 30 \text { days, n (\%) }\end{array}$} \\
\hline Minor wound & 15 (31.25) & $21(27.27)$ & .663 \\
\hline Major wound & 4 (8.33) & 12 (15.58) & .283 \\
\hline Pelvic abscess & $6(12.50)$ & $3(3.90)$ & .085 \\
\hline $\begin{array}{l}\text { Other post-operative } \\
\text { complications } 30 \text { days (eg, } \\
\text { urinary, respiratory, ileus, } \\
\text { kidney failure), n (\%) }\end{array}$ & $19(39.58)$ & $19(24.68)$ & .078 \\
\hline $\begin{array}{l}\text { Length of hospital stay, days } \\
\text { (SD) }\end{array}$ & $6.43(3.87)$ & $5.92(4.11)$ & .247 \\
\hline Type of discharge, n (\%) & & & .001 \\
\hline Home & $26(66.67)$ & 62 (91.18) & \\
\hline Rehabilitation & $13(33.33)$ & $6(8.82)$ & \\
\hline $\begin{array}{l}\text { Re-admissions within } 30 \mathrm{~d}, \mathrm{n} \\
\text { (\%) }\end{array}$ & $10(20.83)$ & $8(10.39)$ & .106 \\
\hline $\begin{array}{l}\text { Re-operations within } 30 \mathrm{~d}, \mathrm{n} \\
\text { (\%) }\end{array}$ & $4(8.33)$ & $5(6.49)$ & .732 \\
\hline $\begin{array}{l}\text { Re-operations within } 60 \mathrm{~d}, \mathrm{n} \\
\text { (\%) }\end{array}$ & $2(4.26)$ & $2(2.60)$ & .634 \\
\hline $\begin{array}{l}\text { Length of post-operative } \\
\text { follow-up, months (SD) }\end{array}$ & $25.58(17.15)$ & $14.38(13.77)$ & $<.001$ \\
\hline Parastomal hernia, n (\%) & $15(35.71)$ & $7(9.86)$ & .001 \\
\hline
\end{tabular}

model did not reach statistical significance (obesity, previous abdominal surgery and intraoperative complication) (Appendix S1).

Parastomal hernia rate remained significantly lower in the RAPR group after multivariate logistic regression (OR 0.13, $P=.002$ ) (Appendix S2). The only statistically significant confounding factor was additional procedure (OR 0.13, $P=.002$ ). Age older than 75 years and high-volume surgeon also approached statistical significance (respectively OR 4.37, $P=.057$ and OR 0.21, $P=.084$ ).

RAPR patients in the multivariate model also less needed rehabilitation at discharge (OR 0.16, $P=.006$ ) independently from patientrelated variables or surgeon's experience (Appendix S3). As such, intraoperative complication was the only confounding factor almost reaching statistical significance (OR 4.25, $P=.051)$.

\section{4 | DISCUSSION}

In this cohort, RAPR appeared to be feasible and safe.

With comparable oncologic outcomes, RAPR led to significant reduction of $\mathrm{OR}$ time and parastomal hernia rate as compared to hybrid approach.

In an oncologic point of view, the main issues of APR are CRM involvement and specimen perforation, as these are thought to be responsible for high cancer recurrence rate after APR. Moreover, recent analysis of the United States National Cancer Database showed a significant increase in positive surgical margins for colon and rectal cancer between 1998 and $2012 .{ }^{15}$ CRM involvement in our cohort was $18.75 \%$ in the HAPR group and $14.29 \%$ in the RAPR group $(P=.508)$. This difference, although not statistically significant, may be related to more frequent extra-levator resections in the RAPR group $(45.5 \%$ vs $4.2 \%$ in HAPR group, $P<.001$ ). Results in both groups, however, showed low CRM involvement as compared with existing literature. In a large Swedish national registry-based observational cohort study, Prytz et al found CRM involvement in $28 \%$ of cases after standard APR and 29\% after extra-levator APR (727 patients analyzed). ${ }^{16}$ Other European results also show high rate of CRM involvement. Analyzing 300 APR from 11 European centers, West et al found $49.6 \%$ CRM involvement with standard APR, but significant reduction to $20.3 \%$ with extra-levator APR $(P<.001) .{ }^{17} \mathrm{Simi}-$ larly, West et al described intraoperative specimen perforation (IOP) rate of $28.2 \%$ after standard APR and $8.2 \%$ after extra-levator APR $(P<.001)$. In our cohort, IOP rate was $12.50 \%$ in the HAPR group and $6.49 \%$ in the RAPR group $(P=.332)$.

Our results are consistent with findings from Kim et $\mathrm{al}^{12,18}$ who compared outcomes from 40 robotic APR to 78 open APR and found a reduction from $14 \%$ to $3 \%$ of $C R M$ involvement in the robotic group; although under statistical significance limit $(P=.057)$ because of small number of events.

These findings demonstrate appropriate pathologic-oncologic results of robotic APR. This could indicate a trend towards improvement of oncologic outcomes but must be interpreted with caution because of limitations of retrospective design. Considering prospective studies, ROLAAR trial ${ }^{19}$ randomized laparoscopic and robotic rectal resections for cancer. In this study, 234 patients were included in the laparoscopic group of which 42 APR, and 237 patients were included in the robotic group of which 43 APR. No significant oncologic benefit of robotic approach was found for rectal cancer in general, but no subgroup analysis of the APR patients was run. Main outcome of ROLAAR trial, rate of conversion to open surgery, showed small nonsignificant reduction of conversion rate in robotic group (8.1\%) vs laparoscopic group (12.2\%, $P=.160)$. According to authors, however, surgeons performing procedures in this study were expert laparoscopic rectal surgeons, but still in their learning phase of robotic approach. Comparatively, in the present study, very low conversion rates were found, especially in RAPR (2.6\%). Robotic surgery may thus help to reduce conversion rate during APR. This assumption is supported by recent meta-analysis from Prete et al for rectal cancer surgery in general. ${ }^{20}$ COLOR II trial showed that minimally invasive colorectal procedures lead to less surgical trauma and functional complications. ${ }^{21}$ Reducing conversion rate in rectal cancer surgery may thus be a major advantage of robotic approaches.

Operative time, however, was identified as a major pitfall of this approach in the meta-analysis of Prete et al. Strategies to improve this specific outcome are thus needed, such as the totally robotic APR.

Data comparing hybrid and totally robotic approach for rectal cancer treatment are scarce. In early robotic experience, hybrid 
procedures are usually performed. Depending on surgeon volume, the technique will often move to totally robotic procedures rather than keeping a hybrid approach. Although using laparoscopy for easier parts of robotic procedures is thought to save some time, our data suggest that time spared by performing colonic mobilization laparoscopically in hybrid approach may be not so important and may not compensate time lost in setup modifications. As such, mean operative time was almost 40 minutes shorter with RAPR. After multivariate analysis, decreased operative time remains statistically significant, regardless of obvious confounding factors (surgeon's experience, obesity, and additional procedure) and the fact that $10.4 \%$ of RAPR patients were turned into prone position during the procedure vs none in HAPR group. Thus, transition to totally robotic approach tends to improve surgical workflow and operative time independently from other time consuming factors, as it has been described previously in other procedures such as bariatric surgery. ${ }^{22}$

Outcomes such as in-hospital length of stay, minor wound complications, pelvic abscess rate, readmission and reoperation within 30 days suggest tendency towards reduced surgical trauma after RAPR, although no conclusion can be made as these results were not statistically significant. Lower parastomal hernia rate observed in RAPR group, even after multivariate adjustment including length of follow-up, also suggests reduced parietal trauma as there was no difference in terms of stoma hernia prevention in both groups; but this result must obviously be interpreted with caution as the physiologic explanation remains disputable. Home discharge was significantly improved in RAPR groups, both after univariate and multivariate analysis, and was not related with traditional factors such as age or comorbidities. These findings may of course be related to shorter procedures in RAPR group, as shorter operative time are known to improve such outcomes. ${ }^{23}$ Another hypothesis could be related to abdominal wall stress during procedure. Robotic systems may allow reduced parietal trauma compared with long rigid laparoscopic instruments, as articulated tips of robotic instruments limit leverage forces applied on abdominal wall. This concept has been described in studies comparing laparoscopic and robotic approach for hysterectomy, ${ }^{24-26}$ where trocars placements are very similar to those of APR. Thus, limiting abdominal wall tensions, totally robotic procedures may theoretically improve functional outcomes as compared with hybrid procedures.

Conclusions must be careful because of obvious study shortcomings. Although interesting results were found compared with existing literature, no direct comparison can be made between this robotic cohort and standard open or laparoscopic approaches. Retrospective nature of data implies inherent biases that limit significance and generalization of findings. Authors concede strong interest in robotic surgery, which may alter their interpretation.

Conversely, sample size for such highly specialized procedure is worth noting and adds to study validity. Results compared with existing literature are encouraging, especially considering various robotic experience and daily practice of participating surgeons. Furthermore, this study adds some new data to orientate technical choice between hybrid and totally robotic procedures in rectal cancer surgery.

\section{5 | CONCLUSION}

In this cohort of robotic APR, totally robotic approach is safe, feasible, and leads to significant reduction of OR time and possibly reduced surgical trauma as characterized by fewer parastomal hernias and fewer need for rehabilitation at discharge. No significant difference in terms of oncological outcomes or other complications were found. Thus, when deciding of robotic approach for APR, totally robotic approach seems advisable. In addition, global oncologic and functional results from this cohort as compared to existing literature show robotic APR to be promising technique to improve low rectal cancer care. These findings have yet to be confirmed by further prospective studies.

\section{ACKNOWLEDGEMENTS}

No acknowledgment.

\section{DISCLOSURES}

Dr Douissard has no conflict of interest or financial ties to disclose pertinent to this work. Outside the scope of this work, Dr Douissard reports nonfinancial support from Intuitive Surgical Inc and personal fees from Verb Surgical Inc

Dr Obias has nothing to disclose.

Dr Johnson has no conflict of interest or financial ties to disclose pertinent to this work. Outside the scope of this work, Dr Johnson reports personal fees from Intuitive Surgical Inc.

Dr Hagen has no conflicts of interest or financial ties to disclose pertinent to this work. Outside the scope of this work, Dr Hagen received personal fees from Intuitive Surgical Inc. and Ethicon Endosurgery and nonfinancial support from Intuitive Surgical Inc and Ethicon Endosurgery.

Dr. Keller has nothing to disclose.

Dr. Ouellette has nothing to disclose.

Dr. Hellan has nothing to disclose.

\section{ORCID}

Jonathan Douissard (D) https://orcid.org/0000-0002-3931-3157

Monika E Hagen (D) https://orcid.org/0000-0003-0158-1559

\section{ENDNOTES}

Note. Model $\chi^{2}=25.16, P=.003$. Pseudo $R^{2}=0.23$.

Note. Model $\chi^{2}=23.41, P=.005$. Pseudo $R^{2}=0.23$.

\section{REFERENCES}

1. Nielsen LB, Wille-Jorgensen P. National and international guidelines for rectal cancer. Colorectal Dis. 2014;16(11):854-865.

2. Hawkins AT, Albutt K, Wise PE, et al. Abdominoperineal resection for rectal cancer in the twenty-first century: indications, techniques and outcomes. J Gastrointest Surg. 2018;22:1477-1487.

3. Zhang X, Wu Q, Hu T, Gu C, Bi L, Wang Z. Laparoscopic versus conventional open abdominoperineal resection for rectal cancer: an updated systematic review and meta-analysis. J Laparoendosc Adv Surg Tech A. 2018; 28(5):526-539.

4. Baek SJ, Kwak JM, Kim J, Kim SH, Park S. Korean Association of Robotic Surgeons Study G. robotic rectal surgery in Korea: analysis of a nationwide registry. Int J Med Robot. 2018;14(3):e1896. 
5. Hellan M, Ouellette J, Lagares-Garcia JA, et al. Robotic rectal cancer resection: a retrospective multicenter analysis. Ann Surg Oncol. 2015; 22(7):2151-2158.

6. Pigazzi A, Ellenhorn JD, Ballantyne GH, Paz IB. Robotic-assisted laparoscopic low anterior resection with total mesorectal excision for rectal cancer. Surg Endosc. 2006;20(10):1521-1525.

7. Scarpinata R, Aly EH. Does robotic rectal cancer surgery offer improved early postoperative outcomes? Dis Colon Rectum. 2013;56 (2):253-262.

8. Ng SS, Lee JF, Yiu RY, Li JC, Hon SS. Telerobotic-assisted laparoscopic abdominoperineal resection for low rectal cancer: report of the first case in Hong Kong and China with an updated literature review. World J Gastroenterol. 2007;13(17):2514-2518.

9. Bae SU, Saklani AP, Hur H, Min BS, Baik SH, Kim NK. Robotic interface for transabdominal division of the levators and pelvic floor reconstruction in abdominoperineal resection: a case report and technical description. Int J Med Robot. 2015;11(3):296-301.

10. Tokuoka M, Ide $Y$, Takeda M, et al. Single-incision plus one-port laparoscopic abdominoperineal resection with bilateral pelvic lymph node dissection for advanced rectal cancer: a case report. Int Surg. 2015; 100(1):15-20.

11. Moghadamyeghaneh Z, Phelan M, Smith BR, Stamos MJ. Outcomes of open, laparoscopic, and robotic abdominoperineal resections in patients with rectal cancer. Dis Colon Rectum. 2015;58(12):11231129.

12. Kim JC, Kwak JY, Yoon YS, Park IJ, Kim CW. A comparison of the technical and oncologic validity between robot-assisted and conventional open abdominoperineal resection. Int J Colorectal Dis. 2014;29 (8):961-969.

13. Eftaiha SM, Pai A, Sulo S, Park JJ, Prasad LM, Marecik SJ. Robotassisted abdominoperineal resection: clinical, pathologic, and oncologic outcomes. Dis Colon Rectum. 2016;59(7):607-614.

14. American Joint Committee on Cancer. Colon and rectum cancer staging. 8th edition. 2016.

15. Orosco RK, Tapia VJ, Califano JA, et al. Positive surgical margins in the 10 Most common solid cancers. Sci Rep. 2018;8(1):5686.

16. Prytz $M$, Angenete E, Bock D, Haglind E. Extralevator abdominoperineal excision for low rectal cancer-extensive surgery to be used with discretion based on 3-year local recurrence results: a registry-based, observational national cohort study. Ann Surg. 2016; 263(3):516-521.

17. West NP, Anderin C, Smith KJE, Holm T, Quirke P. Multicentre experience with extralevator abdominoperineal excision for low rectal cancer. Brit J Surg. 2010;97(4):588-599.

18. Kim JC, Lee JL, Kim CW. Comparative analysis of robot-assisted vs open abdominoperineal resection in terms of operative and initial oncological outcomes. Annals of Surgical Treatment and Research. 2018;95(1):37-44.

19. Jayne D, Pigazzi A, Marshall H, et al. Effect of robotic-assisted vs conventional laparoscopic surgery on risk of conversion to open laparotomy among patients undergoing resection for rectal cancer: the ROLARR randomized clinical trial. Jama. 2017;318(16):1569-1580.

20. Prete FP, Pezzolla A, Prete F, et al. Robotic versus laparoscopic minimally invasive surgery for rectal cancer: a systematic review and meta-analysis of randomized controlled trials. Ann Surg. 2018;267(6): 1034-1046.

21. Bonjer HJ, Deijen CL, Abis GA, et al. A randomized trial of laparoscopic versus open surgery for rectal cancer. New England Journal of Medicine. 2015;372(14):1324-1332.

22. Bindal V, Gonzalez-Heredia R, Masrur M, Elli EF. Technique evolution, learning curve, and outcomes of 200 robot-assisted gastric bypass procedures: a 5-year experience. Obes Surg. 2015;25(6):9971002.

23. Bailey MBDD, Vargas HD, Evers BM, McKenzie SP. Longer operative time: deterioration of clinical outcomes of laparoscopic colectomy versus open colectomy. Dis Colon Rectum. 2014;57(5):616-622.

24. Martino MA, Shubella J, Thomas MB, et al. A cost analysis of postoperative management in endometrial cancer patients treated by robotics versus laparoscopic approach. Gynecol Oncol. 2011;123(3): 528-531.

25. Chiu LH, Chen CH, Tu PC, Chang CW, Yen YK, Liu WM. Comparison of robotic surgery and laparoscopy to perform total hysterectomy with pelvic adhesions or large uterus. J Minim Access Surg. 2015;11 (1):87-93.

26. Leitao MM, Malhotra V, Briscoe G, et al. Postoperative pain medication requirements in patients undergoing computer-assisted ("robotic") and standard laparoscopic procedures for newly diagnosed endometrial cancer. Ann Surg Oncol. 2013;20(11):3561-3567.

\section{SUPPORTING INFORMATION}

Additional supporting information may be found online in the Supporting Information section at the end of this article.

How to cite this article: Douissard J, Obias V, Johnson CS, et al. Totally robotic vs hybrid abdominoperineal resection: $A$ retrospective multicenter analysis. Int J Med Robot. 2020;1-7. https://doi.org/10.1002/rcs.2073 